THURSDAY, MARCH 29, I9r7.

\section{FISH MIGRATION.}

The Migrations of Fish. By Prof. Alexander Meek. Pp. xviii +427. (London: Edward Arnold, I916.) Price I6s, net.

UNDER the stimulus, and largely by the instrumentality, of the International Council for the Investigation of the Sea, enormous progress has been made in marine biological research in its bearings upon eccuomic fishery problems since the founding of that body in 1902 . The lapse of its active functions pending the settlement of the question of the "freedom of the seas" affords a convenient opportunity for considering the general results achieved, and thus the time is ripe for the appearance of Prof. Meek's volume, the material for which has been gathered from the numerous publications of fishery investigators in this and other countries. The book, however, is not merely a compendium or plain digest of other men's work, but possesses an individuality of treatment which is the author's own. While practically all aspects of modern fishery research-or at least their results-are set forth in this treatise, which thus affcrds far more subject-matter than the title implies, the main theme is the development of a theory of migration at various stages of growth in relation to currents. In this connection Prof. Meek introduces the terms denatant and contranatant. These are useful words, and will doubtless find permanent employment, but the idea tends to be somewhat overdriven, and the referring of migrations to one or other of these two classes, while satisfying a desire for logical completeness and formal systematisation, is liable to give rise to misapprehension in omitting consideration of all the factors involved in fish migration.

The rather self-evident fact that the pelagic ova and larvæ of fishes will migrate passively in the same direction as the mass of water which constitutes their habitat-or, in the author's terms, will migrate denatantly - is a fundamental factor in the distribution of fish species and is rightly emphasised. Also, if A represents the locus of a spawning ground, and B the area to which the passive migration of the early planktonic stages is made and where the individuals grow to maturity, then, if the mature fish return for spawning to their natal area $\mathrm{A}$, the spawning migration from $B$ to $A$ will be against the direction of the current which was responsible for their first passive migration. This is described as a contranatant migration. In our opinion this mechanical and frequently misleadingly simple representation of the movements of the older stages leads one very little towards a scientific understanding of the migrations of fishes. The author apparently belongs to that school of ichthyologists who depreciate the value of hydrographical research in relation to the problems associated with fish life. In the preface he says: "It is obvious that currents are importantly associated with migration, but beyond this I have not found it necessary to introduce hydrographical considerations." One may mention the researches of Schmidt and other Scandinavian naturalists upon the migrations of cod, plaice, eels, etc., as demonstrating the fundamental importance of hydrographical factors in determining the spawning migrations of these species, while English investigations also point to the correlation between hydrographical conditions -i.e. temperature and salinity of water-and the movements of fishes. It may be that the author considers such correlations insufficiently established as yet; but in ignoring them he would appear, consciously or unconsciously, to dissociate himself from the trend of present-day fishery research.

The omission of reference to food and feeding habits also detracts from the value of this work as a treatise on migration, and further deepens the impression of a too mechanical and pedantically systematised presentation of the phenomena of migration, in terms of which the following is a sample: "The mackerel are denatant migrants in the young condition, and it is evident that the denatant migration is the dominant feature of the migrations when they become mature. It is, as a fact, usually denatant, but in some cases it may be said to be denatant in direction only."

Since the larval stages of practically all fishes are planktonic, the exposition of the idea of denatant migration is carried laboriously, but without any serious hitch, throughout the chapters on the various species. In suggesting that the landward migration of the leptocephalus larvæ of the eel is purely a matter of passive denatant drift, however, the author surely departs from the views of the authorities on the subject. In fact, leptocephali, though doubtless assisted by the drift of Atlantic water towards the European coasts, have quite considerable swimming power.

The distribution and migratory habits of North Sea plaice have been investigated by the international collaborators with a thoroughness and with conspicuously conclusive results which may be said without bias to constitute a monumental fabric of fishery research. These results being available in reports published between 1904 and 1916, it is a drawback that detailed consideration of plaice migrations should have been limited to the relatively insignificant and unrepresentative fraction of the plaice fauna which occurs off the Northumberland coast and in the Firth of Forth.

After the unfortunate quotation from Izaak Walton in the introduction repeating the old but now quite exploded notion that a salmon returns from the sea to the river which it left as a smolt or samlet "usually about six months after," one naturally approaches the chapter on Salmonidæ with shaken confidence. The above erroneous view is repeated on p. Irg in dealing with the definition of a grilse, and the statement that male smolts are present on the spawning beds is a misuse of terms. Nor is it correct to assume that female salmon must have spent at least two winters in the sea before spawning, since female grilse are quite common, though not propor- 
tionately so numerous as males. Again, in the life of salmon at sea, while growth is more rapid in summer than in winter, it is erroneous to say that feeding is practically confined to the summer.

Regarding purely marine species, the general information is voluminous and authoritative. The author should, however, revise his impressions as to the relative sizes of the two sexes of the conger; the species of the dog-fish pest of the English Channel, which is predominantly Acanthias vulgaris, and not Scyllium canicula; and the adequacy of the scale-reading method for the determination of the age of haddock.

Notwithstanding what we have criticised as faults of commission or omission in this substantial work, it is one which no one interested in fishery science or desirous of an up-to-date grasp of some of the phenomena underlying practical fishery questions can afford to overlook.

\section{THE PARTITIONS OF NUMBERS.}

Combinatory Analysis. By Major P. A. MacMahon. Vol. ii. Pp. xix +340 . (Cambridge: At the University Press, 1916.) Price $18 s$. net. WHEN the first volume of this work was noticed in these columns, the reviewer of that volume expressed the hope that the second would not be long delayed. This hope has been fulfilled, and the reader can now obtain, for the first time, a connected account of all the modern work-so largely due to Major MacMahon himself-which has been done in connection with the partitions of numbers and with allied problems. For the more historical side of the subject the author refers the reader to Netto's "Combinatorik," and he is more concerned to present the newer processes and ideas which lie at the root of the present rapid development of the subject, and have not hitherto found a place in any book. Thus only the earlier sections of the present work overlap that of Netto, and certain investigations which are arithmetical rather than algebraical are dismissed briefly.

It is not possible, in a short space, even to enumerate the many problems of interest which are discussed in this volume-whether problems of analytical development of functions, or problems of a general interest to the non-mathematician, but the solution of which depends on the partitions of numbers. We must perforce confine attention to certain outstanding features, and make no attempt at a summary of the contents of the work.

The introduction contains a list of the memoirs to which reference is made, and the index to both volumes is at the end of the book. Chap. i. begins with Euler's "intuitive" theory of partitions, and gives an account also of the powerful graphical method devised by Ferrers, and used so much by Sylvester. In the next chapter more special attention is given to Durfee's method of studying the graph of a partition, and a very complete set of expansions of generating functions is a notable feature.

NO. 2474, VOL. 99]
The most remarkable of such expansions are the pair discovered intuitively by Ramanujan. Only a few months ago it was found, by Ramanujan himself, that all the arithmetical labour of many mathematicians who have tested one of these expansions, for example, to eightynine terms in the supposed default of a real proof, has been wasted, for the theorem was, in fact, proved by Rogers more than twenty years ago, and at the time attracted little attention. Major MacMahon has made some very significant applications of these theorems to a branch of the theory of partitions on which work was scarcely possible before their discovery.

The author has succeeded in basing the theory of partitions upon the theory of Diophantine inequalities. This method is much more fundamental than that of Euler, and its use has rendered the theory of partitions highly general, so that it has now quite lost its earlier characterundoubtedly hitherto the cause of its comparative neglect by mathematicians--of a set of somewhat isolated, though elegant, solutions of special problems. It seems fair to claim, in fact, that we are indebted to the author for a new branch of mathematics, and a branch which must dominate future treatises which make a prominent use of algebraical processes.

Many chapters must be passed over without specific reference, but special mention must be made of those on magic squares, partitions in two dimensions, and the further theory of the Latin square. It is probable that many mathematicians are not aware of the extent to which these subjects have developed, and of the field of work which is still unexplored, and capable of yielding results which are fundamental not alone in connection with the partitions of numbers. By collecting these researches, which are so very much his own, from their hiding-places in scientific memoirs into these two volumes, the author has done much towards the promotion of a more general outlook on the whole range of analytical work usually classed somewhat vaguely as "algebra."

\section{OUR BOOKSHELF.}

Nature Study Lessons Seasonally Arranged. By J. B. Philip. Pp. ix +147 . (Cambridge: At the University Press, 19I6.) Price $2 s$. 6d. net. IT is generally agreed that in the early stages science teaching should consist of "Nature study." But it is seldom that teachers realise that this should afford a sound foundation on which later, more serious, study can securely rest. Mr. Philip's little book is a bright and outstanding exception to the general rule. It concerns itself solely with botanical material in its twelve chapters; but the child of from twelve to fourteen years of age who works through its pages in the course of a year will not merely have learnt to observe, but also will have gained a firm grasp of fundamental botanical principles. From the outset the author is at pains to impress the fact that the 